\title{
THE DIFFICULTIES IN THE DIAGNOSIS OF PULMONARY HYPERTENSION ASSOCIATED WITH CHRONIC LUNG DISEASE
}

DOI: 10.36740/WLek202009109

\author{
Sylwia Łukasik', Dariusz Łukasik', Michał Tomaszewski' , Weronika Topyła ${ }^{1}$, Agnieszka Wojtowska' ${ }^{1}$, \\ Aleksandra Szopa ${ }^{2}$, Andrzej Wysokiński' \\ 'DEPARTMENT OF CARDIOLOGY, MEDICAL UNIVERSITY OF LUBLIN, LUBLIN, POLAND \\ 2DEPARTMENT OF APPLIED AND SOCIAL PHARMACY, LABORATORY OF PRECLINICAL TESTING, MEDICAL UNIVERSITY OF LUBLIN, LUBLIN, POLAND
}

\begin{abstract}
Introduction: Chronic lung disease (WHO group 3) is the second leading cause of pulmonary hypertension (PH). In turn, the development of PH influences the course of lung disease, worsening the clinical symptoms and prognosis.

The aim: To analyse the difficulties in the diagnosis of pulmonary hypertension due to chronic lung disease.

Review and Discussion: According to recent literature, PH in the course of lung diseases develops as a result of both "parenchymal" and vascular pathology in patients with a genetic predisposition. Prolonged infection (especially viral) may be an additional promoting factor. Elevation of pulmonary arterial pressure (PAP) is usually moderate and correlates with severity of lung disease. In a small minority, PAP may reach that seen in WHO group 1 pulmonary arterial hypertension (PAH).

Conclusions: Echocardiography and right heart catheterization are the principal tools for the diagnosis of PH in chronic lung diseases. Unfortunately, current medications for treating PAH have not shown benefit in controlled trials of group $3 \mathrm{PH}$, hence their routine use is not recommended. Patients with severe group $3 \mathrm{PH}$ should be considered for referral to expert centres or entry into clinical trials.
\end{abstract}

KEY WORDS: pulmonary hypertension, chronic lung disease, chronic obstructive pulmonary disease, interstitial lung disease, idiopathic pulmonary fibrosis

Wiad Lek. 2020;73(9 p. I):1853-1860

\section{INTRODUCTION}

In any lung disease, the development of $\mathrm{PH}$ is related to a deterioration of exercise tolerance, worsening of hypoxaemia and shorter survival. The severity of $\mathrm{PH}$ is usually poorly related to the severity of the underlying lung disease. The most common factors for the presence of $\mathrm{PH}$ in these patients are an out-of-proportion low DLCO and a low $\mathrm{pCO}_{2}[1]$.

This article provides an update on pulmonary hypertension $(\mathrm{PH})$ associated with chronic lung disease (CLD), with the main focus being on chronic obstructive pulmonary disease (COPD) and interstitial lung disease (ILD) .

\section{DEFINITION AND CLASSIFICATION}

The normal pulmonary vasculature is a low-pressure system, with less than one tenth the resistance to flow estimated in the systemic vasculature [2]. Pulmonary hypertension in the course of lung diseases can be categorized as a form of precapillary pulmonary hypertension. This is the hemodynamic state with the mean pulmonary arterial pressure (PAPm) elevated above an average of $25 \mathrm{mmHg}$ at rest, pulmonary capillary wedge pressure (PCWP) not exceeding $15 \mathrm{mmHg}$ and pulmonary vascular resistance (PVR) greater than 3 Wood Units (WU) as assessed by right heart catheterization (RHC) [3].
Those patients with severe $\mathrm{PH}(>40 \mathrm{mmHg}$ ) have a significant increase in PVR (around $10 \mathrm{WU}$ ), however, even when mPAP is lower (20-30 $\mathrm{mmHg})$, PVR still remains generally $>3 \mathrm{WU}$. It is well recognized that even a modest elevation in mPAP $(20-29 \mathrm{mmHg})$ is associated with poor prognosis [4].

In 2015, the European Society of Cardiology and European Respiratory Society published

new guidelines on the diagnosis and treatment of pulmonary hypertension (PH). $\mathrm{PH}$ due to

lung diseases and/or hypoxia was classified as a separate entity (Table 1) [3].

$\mathrm{PH}$, according to the current World Organization (WHO) classification, is also listed under various group headings due to diffuse parenchymal lung disease (DPLD) effects. For example, in the course of idiopathic pulmonary fibrosis (IPF), non-specific interstitial pneumonia (NSIP), other types of interstitial pneumonia, hypersensitivity pneumonitis (HP), eosinophilic pneumonitis, and pulmonary alveolar proteinosis, it is listed in group 3; due to sarcoidosis, pulmonary Langerhans cells histiocytosis (PLCH), lymphangioleiomyomatosis (LAM) and vasculitis, it is placed within group 5; due to connective tissue diseases with predominant vascular involvement, it is classified within group 1 [3].

Pathologic changes that result in pulmonary hypertension from group 3 chronic lung disease primarily 
Sylwia Łukasik et al.

Table 1. Comprehensive clinical classification of pulmonary hypertension according to ESC 2015 [3].

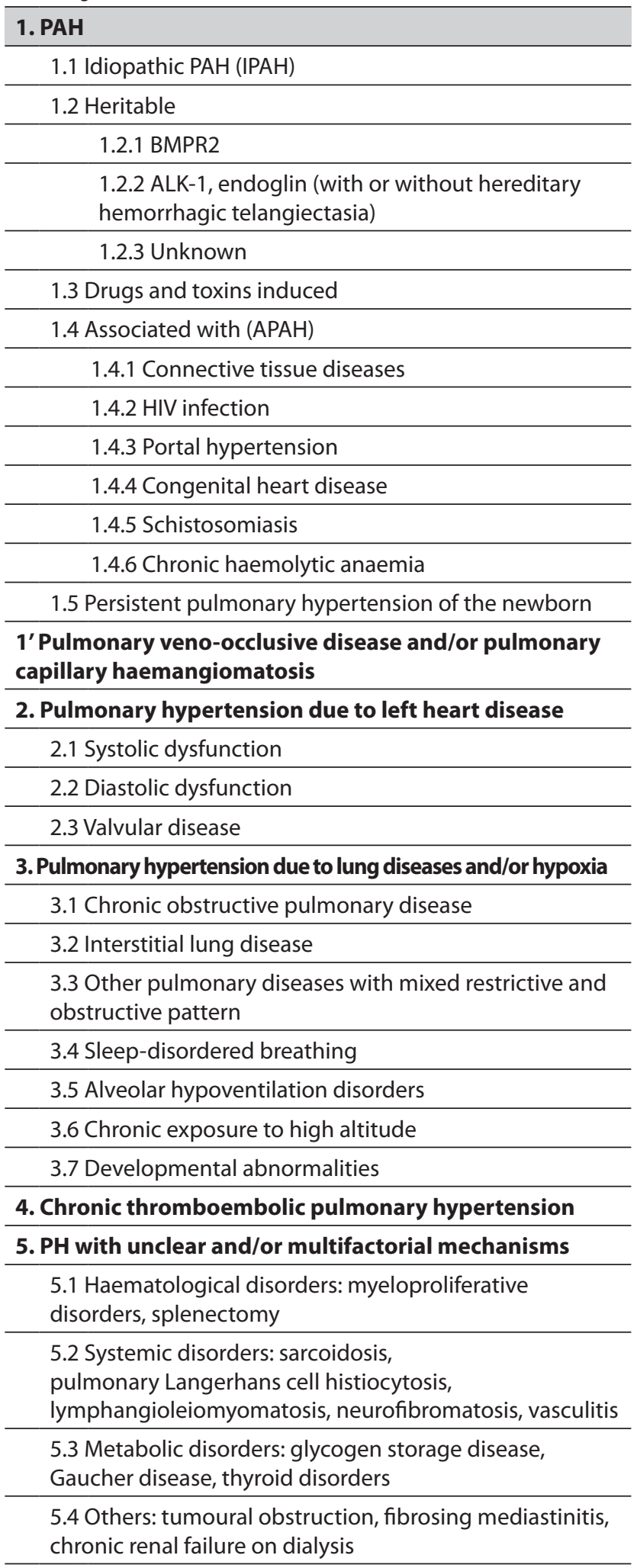

target pulmonary arterioles, the same location as abnormalities in group 1 pulmonary arterial hypertension (PAH) and group 4 chronic thromboembolic pulmonary hypertension (CTEPH), whereas abnormalities that result in $\mathrm{PH}$ in group 2 left heart disease (PH-LHD) are found mostly on the venous side of the pulmonary circulation. Interestingly, several challenging phenotypes display features that overlap between two or more WHO PH groups [4].

\section{THE AIM}

The aim of the review is to analyse the difficulties in the diagnosis of pulmonary hypertension due to chronic lung disease.

\section{REVIEW}

\section{EPIDEMIOLOGY AND CLINICAL CHARACTERISTIC OF PH IN LUNG DISEASES}

\section{CHRONIC OBSTRUCTIVE PULMONARY DISEASE}

Pulmonary hypertension is common in chronic obstructive pulmonary disease (COPD), with the incidence being 25 90\%. Indeed, several studies in patients with spirometric Global Initiative for COPD stage IV show that up to $90 \%$ have mPAP above $20 \mathrm{mmHg}$, with most ranging between 20 and $35 \mathrm{mmHg}$. Severe pulmonary hypertension, however, is quite rare (1-3\%) [5], and why only a minority of COPD patients develop severe pulmonary hypertension is still uncertain.

According to recent data, specific genetic signatures, prolonged infections (especially viral), as well as pulmonary or artery smooth muscle cell senescence caused by telomere shortening or oxidative stress, may contribute to the pulmonary hypertension associated with chronic lung diseases $[5,6]$. Moreover, extensive pulmonary vessel remodelling with prominent intimal thickening, medial hypertrophy and muscularization of the small arterioles are cardinal pathological features of $\mathrm{PH}$ in COPD.

Furthermore, there is a group of patients representing a "pulmonary vascular COPD phenotype", characterized by less severe airflow limitation, hypoxaemia, very low diffusing capacity of the lung for carbon monoxide (DLCO), normo- or hypocapnia and a cardiovascular exercise limitation profile. These patients are more prone to develop $\mathrm{PH}$ in the future [7].

Although the term "out of proportion" pulmonary hypertension is still widely used, new guidelines recommend to use the term "severe pulmonary hypertension" if mean pulmonary arterial pressure is at least $35 \mathrm{mmHg}$ or the cardiac index (CI) is less than $2.01 / \mathrm{min} / \mathrm{m}^{2}$ on RHC. It has previously been well established that the presence of even moderate $\mathrm{PH}$ has a stronger association with mortality in COPD than does forced expiratory volume in $1 \mathrm{~s}$ (FEV1) or gas exchange variables. Moreover, the vascular lesions in severe COPD-PH patients are morphologically similar to those in idiopathic PAH (IPAH) [5]. In addition, an enlarged pulmonary artery diameter, as detected by computed tomography (CT) scan, predicts hospitalisation due to acute COPD exacerbation [8]. 


\section{IDIOPATHIC PULMONARY FIBROSIS AND OTHER IDIOPATHIC INTERSTITIAL PNEUMONIAS}

Interstitial lung diseases (ILD) include a heterogenous group of inflammatory diseases with common functional characteristics (restrictive lung physiology and impaired gas exchange) resulting in alveolar hypoxemia and irreversible fibrosis. The prevalence of PH in IPF is high and varies depending on the stage of disease. In idiopathic pulmonary fibrosis (IPF), $\mathrm{PH}$ was found in $8-11 \%$ of all patients with early stage disease $[9,10], 32-46 \%$ of those with advanced disease $[11,12]$, and even in $86 \%$ of all patients at the time of referral for lung transplantation [13]. In the majority of the patients, mPAP was within $25-40 \mathrm{mmHg}$, mPAP exceeding $40 \mathrm{mmHg}$ was found in only $2-9 \%$ of the patients examined $[11,12]$. The pathophysiology of $\mathrm{PH}$ due to chronic lung fibrosis is under active investigation. In particular, the roles of the endothelin (ET) system, transforming growth factor (TGF)-b1, connective tissue growth factor (CTGF) activation and oxidative stress are well recognized in both conditions, with obvious interrelationships [14].

Clinically, PH may induce dyspnoea, fatigue and exercise limitation - symptoms which are also features for ILDs. As a result, the diagnosis of $\mathrm{PH}$ may be missed in ILD patients until signs of right heart failure develop. Unfortunately, there is only a poor or even no correlation between $\mathrm{PH}$ severity and lung function impairment or high-resolution CT fibrosis score $[15,16]$. There are data, however, suggesting that patients who have been vulnerable to developing $\mathrm{PH}$ in the course of IPF show increased dyspnea, deterioration of gas exchange at rest, low capacity of lung to diffuse carbon monoxide (DLCO) values, rapid desaturation upon exercise, high brain naturetic peptide (BNP) levels, gross right heart dilation on chest radiography and limitation of exercise capacity caused by circulatory impairment $[11,17,18]$. Still, it is accepted that even mild PH may significantly worsen the prognosis of patients with ILD. It appears that systolic PAP >50 mmHg estimated in Doppler-echocardiography and even invasive mPAP values of $>17 \mathrm{mmHg}$ were related to impaired survival in IPF, with mPAP and forced vital capacity (FVC) being independent predictors of survival $[5,19]$. Moreover, in some studies, the prognosis of $\mathrm{PH}$ in lung fibrosis is not associated with the mPAP values, but to PVR or cardiac index (CI), with CI values $<2.4 \mathrm{l} / \mathrm{min} / \mathrm{m}^{2}$ being correlated with survival of only a few months [20]. Unfortunately, the prognosis of fibrotic idiopathic interstitial pneumonia (IIP) with $\mathrm{PH}$ is worse than IPAH [21].

\section{COMBINED PULMONARY FIBROSIS AND EMPHYSEMA, AND OTHER LUNG DISEASES}

Combined pulmonary fibrosis and emphysema (CPFE) is currently defined by the simultaneous presence of emphysema in the upper lobes and fibrosis in the lower lobes on chest CT. Patients with CPFE are particularly susceptible to develop $\mathrm{PH}$, with available data suggesting a prevalence of $30-50 \%$ [20, 22]. Typically, normal or mildly abnormal lung volumes and the absence of airflow obstruction are associated with a considerably impaired diffusion capacity, significant hypoxaemia and $\mathrm{PH}$. The $\mathrm{PH}$ appears to contribute to the functional limitation in CPFE and results in poor survival $[20,22,23]$.

The prevalence of $\mathrm{PH}$ in patients with pulmonary Langerhans cell histiocytosis is also high. In addition, $\mathrm{PH}$ may develop in patients with chronic hypersensitivity pneumonitis, lymphangioleiomyomatosis, bronchopulmonary dysplasia and cystic fibrosis, and, possibly, lung cancer [3]. Among congenital tissue disease, scleroderma has the highest predisposition to $\mathrm{PH}$ development. The overall incidence of PAH estimated in $\mathrm{RCH}$ is $8-18 \%$ [29].

\section{SARCOIDOSIS}

In sarcoidosis, overall incidence of $\mathrm{PH}$ ranges from 5.7\% to $38-51 \%$, in stage IV disease, up to $74 \%$ in patients referred for lung transplantation [24]. Patients with PH due to sarcoidosis have a reported 5-year survival of $50-60 \%$ [25]. While the majority of these patients have extensive parenchymal disease, it may also occur in patients without pulmonary fibrosis $[26,27]$. The mechanisms underlying $\mathrm{PH}$ in sarcoidosis are complex, and include fibrosis-associated remodelling, pulmonary veno-occlusive-like lesions and obliteration of pulmonary vessels. Pulmonary artery stenosis due to extrinsic compression by lymphadenopathy or mediastinal fibrosis, granulomatous involvement of pulmonary vessels, left ventricular dysfunction, and portopulmonary hypertension are additional factors that have to be taken into account $[28,29]$.

\section{DETECTION OF PH IN CHRONIC LUNG DISEASES (GROUP 3)}

Early recognition of $\mathrm{PH}$ in the course of CLD is pivotal due to several facts:

1. The risk of bleeding during diagnostic lung biopsies is higher in $\mathrm{PH}$ patients.

2. The occurrence of $\mathrm{PH}$ in the patient with hypoxemia is a strong indication for long term oxygen therapy.

3. PH significantly worsens the prognosis of CLD and should be taken into account as an additional indication for lung transplantation in end-stage of the disease.

4. The patients with documented severe $\mathrm{PH}$ in the course of CLDs have the possibility to enter randomized clinical trials with PAH-specific treatment [3].

Unfortunately, in spite of increasing awareness of $\mathrm{PH}$, diagnosis is often delayed. This effect is associated with the shared common symptoms of $\mathrm{PH}$ and respiratory disorders such as dyspnea and exercise limitation. As a general rule, patients presenting symptoms that are more severe than expected based on their pulmonary functional tests results should be further diagnosed, in particular, by echocardiography, to search for concomitant left heart disease or PH. Furthermore, it is recognized that $\mathrm{PH}$ may also occur in non-hypoxemic patients with mild-to-moderate functional impairment and in sarcoidosis without evident features of ILD $[19,28]$. 
Sylwia Łukasik et al.

Table 2. Criteria for pulmonary hypertension based on echocardiography according to ESC 2015 [3].

\begin{tabular}{cccc}
\hline TRV $[\mathrm{m} / \mathrm{sec}]$ & PASP $[\mathbf{m m ~ H g}]$ & Additional PH variables suggestive of PH* & Probability \\
\hline $\mathbf{2 . 8}$ & $\leq 36$ & Lacking & PH unlikely \\
\hline $\mathbf{2 . 8}$ & $\leq 36$ & Present & PH possible \\
\hline $\mathbf{2 . 9 - 3 . 4}$ & $37-50$ & Lacking & \\
\hline$>\mathbf{3 . 4}$ & $>50$ & Present or lacking & PH likely \\
\hline
\end{tabular}

*Increased velocity of pulmonary wave regurgitation, short acceleration time of RV ejection into the PA, increased dimensions of right heart chambers, abnormal shape and movement of interventricular septum, increased RV wall thickness, dilated main PA; TRV - tricuspid regurgitation velocity; PASP pulmonary artery systolic pressure; $\mathrm{PH}$ - pulmonary hypertension; PA - pulmonary artery; RV - right ventricle

The only indication for screening for $\mathrm{PH}$ in patients without the symptoms of $\mathrm{PH}$ involves scleroderma patients. This group of patients generally develop $\mathrm{PAH}$, and targeted therapy for PAH is available. During the Nice Conference, the indicators for screening were established. These include the presence of the SSc spectrum of diseases (SSc, mixed connective tissue disease) with diffusion capacity for carbon monoxide (DLCO) $\leq 60 \%$ of predicted and the disease duration exceeding 3 years. Herein, echocardiography and finally RHC are used to verify the diagnosis $[29,30]$.

Although echocardiography is the most widely used non-invasive tool for screening for CLD-PH, the ability to determine peak tricuspid regurgitation velocity to estimate the right ventricular systolic pressure is limited in these patients (Table 2) $[3,32]$. Alternate echocardiographic measures including right ventricular outflow tract diameter and tricuspid annular plane systolic excursion, while qualitative assessment of right chamber structure and function have been advocated in IPF and COPD [33, 34]. On imaging, the pulmonary artery/aorta diameter ratio $>1$ (range 0.9-1.1) can be useful [35]. On comparing echocardiographic data with RHC in lung disease patients in COPD and diffuse parenchymal lung disease (DPLD), positive predictive values of $32 \%$ and $68 \%$, respectively, and negative predictive values of $93 \%$ and $67 \%$, respectively, were reported [34, 35].

Plasma levels of brain natriuretic peptide (BNP) or $\mathrm{N}$-terminal pro-BNP are elevated in severe CLD-PH, but have less sensitivity and specificity for moderate $\mathrm{PH}$ and may coexist with other heart abnormalities. However, BNP levels are recognized to be strong predictors of mortality in lung disease patients [3]. In addition, pulmonary function tests indicate that both ILD and COPD interfere in respiratory disease, $\mathrm{PH}$ is generally related to a lower DLCO, limited exercise tolerance and more impaired gas exchange at rest or during exercise than expected based on ventilatory impairments [3].

In $\mathrm{PH}$, a restrictive pattern is predominating, nevertheless, a large proportion of patients show bronchial obstruction and hyperinflation due to air-trapping.

The presence of $\mathrm{PH}$ in lung diseases is suspected when significant impairment of restrictive type ventilation reserves such as total lung capacity (TLC) $<70 \%$ of the due value or obstructive value -

FEV1/FVC < LLN (FEV1-forced expiratory volume in 1 second; FVC-forced vital capacity; LLN- lower limit of normal) and FEV $1<60 \%$ of the due value are accompanied by a significant reduction in DLCO $\leq 40 \%$ of the due value $[5,14]$. Significant desaturation during a 6 -minute walk test (below 90\%) and resting hypoxemia $\left(\mathrm{PaO}_{2}<60\right.$ $\mathrm{mmHg}$ ) occur in advanced cases [3].

In a study conducted by Zisman et al. among Ssc patients, the prognostic factor of $\mathrm{PH}$ is greater impairment of DLCO than FVC which results in an increase in FVC / DLCO availability $>1.6-1.8$. At the moment it is not known whether this observation can be extended to other lung diseases [36]. In sarcoidosis, significant pulmonary functional test (PFT) abnormalities appear usually in advanced stages of the disease (stages III and IV) and affect $60 \%$ of all patients. The most typical is a restrictive PFT pattern $(\mathrm{TLC}<\mathrm{LLN})$, occasionally with coexisting bronchial obstruction (FEV1/ FVC $<$ LLN) [37]. Evaluation of pulmonary hypertension $(\mathrm{PH})$ in chronic lung disease is shown in Figure 1 [5].

FEV1: forced expiratory volume in $1 \mathrm{~s}$; FVC: forced vital capacity; CT: computed tomography; PAH: pulmonary arterial hypertension; RCT: randomized controlled trial; DLCO: diffusing capacity of the lung for carbon monoxide; KCO: transfer coefficient of the lung for carbon monoxide. \#: suggestive findings include: 1) symptoms and signs (dyspnoea out of proportion, loud P2, signs of right heart failure, right axis deviation on ECG, elevated natriuretic peptide levels); 2) pulmonary function test abnormalities (low DLCO (e.g $<40 \%$ of predicted), elevated \%FVC/\%DL$\mathrm{CO}$ ratio (lowKCO)); 3 ) exercise test findings (including decreased distance, decreased arterial oxygen saturation or increased Borg rating on 6-min walk test and decreased circulatory reserve, preserved ventilatory reserve on cardiopulmonary exercise testing); and 4) imaging findings (extent of LD, enlarged pulmonary artery segments, increased pulmonary artery/aorta diameter ratio $>1$ on CT). g: signs supporting the diagnosis of $\mathrm{PH}$ include elevated systolic pulmonary arterial pressure and signs of right ventricular dysfunction. However, echocardiography measures are only suggestive and have limited accuracy in patients with CLD. +: strongly consider referring the patient to a $\mathrm{PH}$ expert centre. $\$$ : expert centres should comprise multidisciplinary teams. Any decision for individualized treatment should follow a goal-orientated approach with predefined treatment targets, to be stopped if these targets are not met after a predefined time period.

Right heart catheterization (RHC) remains the gold standard for the diagnosis of CLD-PH. However, it is an 


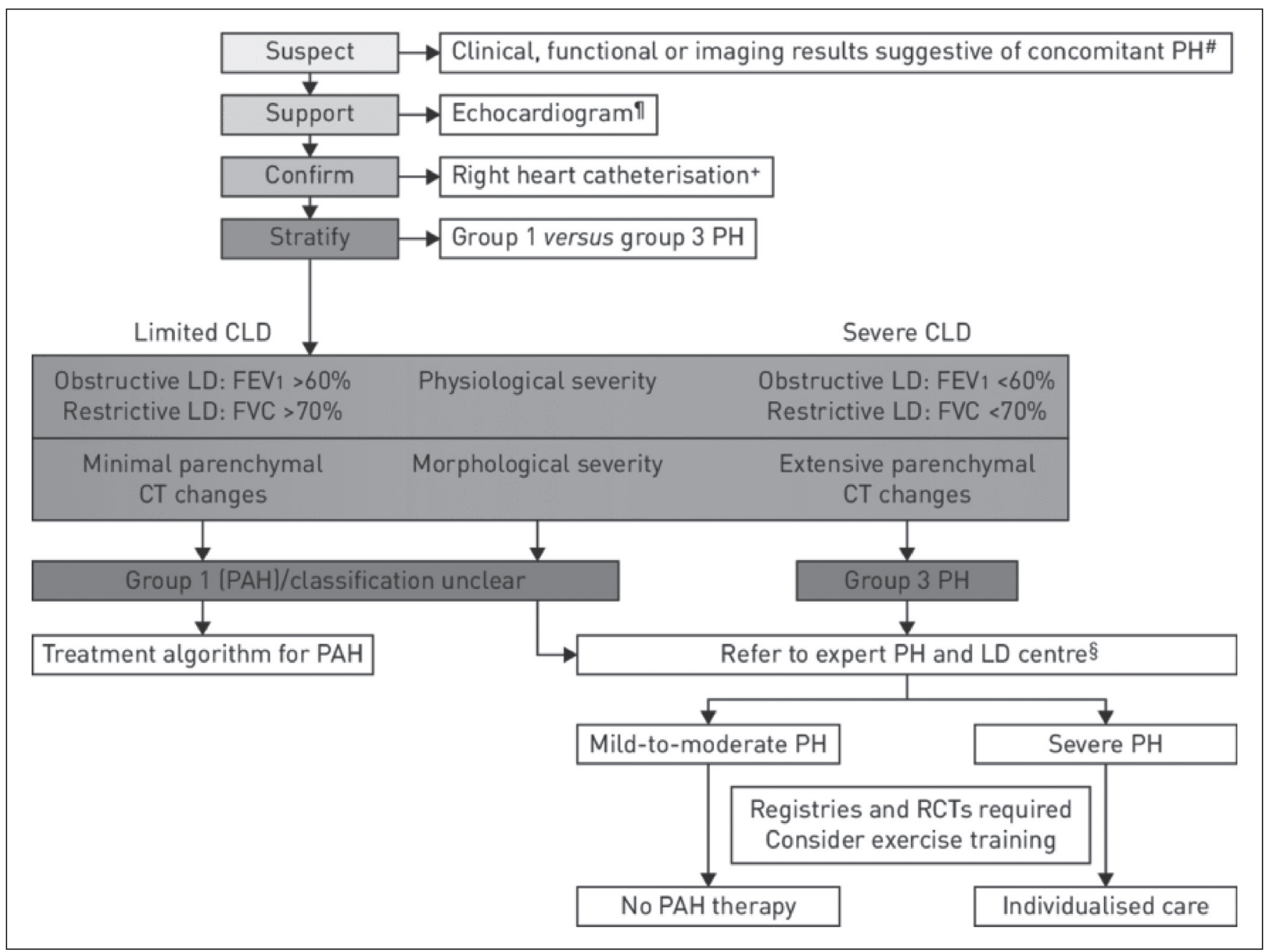

Fig. 1. Evaluation of pulmonary hypertension (PH) in chronic lung disease (CLD) [5].

Table 3. Heamodynamic classification of pulmonary hypertension in chronic lung disease [40].

\begin{tabular}{cc}
\hline CLD without PH & $\begin{array}{c}\mathrm{mPAP}<21 \mathrm{mmHg} \text {, or mPAP 21-24 mmHg with pulmonary vascular } \\
\text { resistance }(\mathrm{PVR})<3 \text { WU }\end{array}$ \\
\hline CLD with PH & $\mathrm{mPAP} 21-24 \mathrm{mmHg}$ with PVR $\geq 3 \mathrm{WU}$, or $\mathrm{mPAP} 25-34 \mathrm{mmHg}$ \\
\hline CLD with severe PH & $\begin{array}{c}\mathrm{mPAP} \geq 35 \mathrm{mmHg} \text {, or } \mathrm{mPAP} \geq 25 \mathrm{mmHg} \text { with low cardiac index } \\
(\mathrm{Cl}<2.0 \mathrm{~L} \cdot \mathrm{min}-1 \cdot \mathrm{m}-2)\end{array}$ \\
\hline
\end{tabular}

Abbreviations: $\mathrm{PH}$, pulmonary hypertension; mPAP, mean pulmonary artery pressure; PVR, pulmonary vascular resistance; WU, Wood units (mmHg/L/ $\min ) ;(\mathrm{l}$, cardiac index

invasive procedure and is not recommended as a mandatory tool in patients with established lung disease if there is no therapeutic or management consequence [38].

RHC should be considered in advanced lung disease in several cases such as: 1) making proper diagnosis or exclusion of $\mathrm{PH}$ in patients for surgical treatments (transplantation, lung volume reduction), 2) suspicion of $\mathrm{PAH}$ or CTEPH, 3) recurrent episodes of RV failure and 4) presence of inconclusive echocardiographic results in cases with a high level of suspicion and potential therapeutic implications [39].

Pressure measurements during RHC in patients with lung disease should take into account exaggerated changes in intrathoracic pressures during the breathing cycle, and a floating average over several breaths (without a breath hold) is suggested for measurement of mean pressures, including the pulmonary capillary wedge pressure. Heamodynamic classification of pulmonary hypertension in chronic lung disease is shown in Table 3 [40].

The routine use of acute vasodilator testing in CLD-PH is not recommended [40]. Furthermore, the spectrum of severity of both the pulmonary vascular and parenchymal lung disease is likely a continuum, which often makes the distinction between group 1 and group $3 \mathrm{PH}$ very difficult.

Differential diagnosis was made according to the criteria proposed in the 5th World PH symposium (Table 4). Criteria favoring group $1 \mathrm{PAH}$ include normal or mildly impaired PFT (FEV1>60\% predicted for COPD; FVC>70\% 


\begin{tabular}{|c|c|c|}
\hline Criteria favouring group 1 (PAH) & Testing & $\begin{array}{l}\text { Criteria favouring group } 3 \\
\text { (PH due to lung disease) }\end{array}$ \\
\hline \multicolumn{3}{|c|}{ Extend of lung disease } \\
\hline $\begin{array}{l}\text { Normal or mildly impaired: } \\
\text { FEV1 }>60 \% \text { pred (COPD) } \\
\text { FVC }>70 \% \text { pred (IPF) } \\
\text { Low diffusion capacity in relation to } \\
\text { obstructive/restrictive changes }\end{array}$ & Pulmonary function testing & $\begin{array}{c}\text { Moderate to very severely impaired: } \\
\text { FEV1 }<60 \% \text { pred (COPD) } \\
\text { FVC }<70 \% \text { pred (IPF) } \\
\text { Diffusion capacity "corresponds" to obstructive/ } \\
\text { restrictive changes }\end{array}$ \\
\hline $\begin{array}{c}\text { Absence of only modest airway or } \\
\text { parenchymal abnormalities }\end{array}$ & High-resolution CT scan & $\begin{array}{l}\text { Characteristic airway and/or parenchymal } \\
\text { abnormalities }\end{array}$ \\
\hline \multicolumn{3}{|c|}{ Haemodynamic profile } \\
\hline Moderate-to-severe PH & $\begin{array}{l}\text { Right heart catherization } \\
\text { Echocardiogram }\end{array}$ & Mild-to-moderate PH \\
\hline \multicolumn{3}{|c|}{ Ancillary testing } \\
\hline Present & $\begin{array}{c}\text { Further PAH risk factors (e.g. HIV, } \\
\text { connective tissue disease, BMPR2 } \\
\text { mutations,etc.) }\end{array}$ & Absent \\
\hline $\begin{array}{c}\text { Features of exhausted circulatory } \\
\text { reserve: } \\
\text { Preserved breathing reserve } \\
\text { Reduced oxygen pulse } \\
\text { Low } \mathrm{CO} / \mathrm{N}_{\mathrm{O} 2} \text { slope } \\
\text { Mixed venous oxygen saturation at } \\
\text { lower limit } \\
\text { No change or decrease in } \mathrm{Pa}_{\mathrm{CO} 2} \text { during } \\
\text { exercise }\end{array}$ & $\begin{array}{l}\text { Cardiopulmonary exercise test }+ \\
\left(\mathrm{Pa}_{\mathrm{CO} 2} \text { particulary relevant in COPD) }\right.\end{array}$ & $\begin{array}{c}\text { Features of exhausted ventilatory reserve: } \\
\text { Reduced breathing reserve } \\
\text { Normal oxygen pulse } \\
\text { Normal } \mathrm{CO} / \mathrm{N}_{\mathrm{O} 2} \text { slope } \\
\text { Mixed venous oxygen saturation above lower } \\
\text { limit } \\
\text { Increase in } \mathrm{Pa}_{\mathrm{CO} 2} \text { during exercise }\end{array}$ \\
\hline
\end{tabular}

Predominant obstructive/ restrictive profile

Predominant haemodynamic profile

PAH: pulmonary arterial hypertension; FEV1: forced expiratory volume in $1 \mathrm{~s}$; COPD: chronic obstructive pulmonary disease; FVC: forced vital capacity;

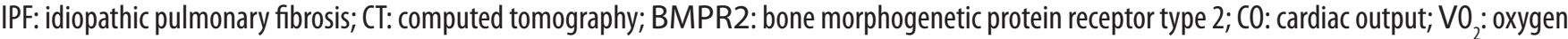
uptake; $\mathrm{PaC} \mathrm{O}_{2}$ arterial carbon dioxide tension. \#: group 2 and 4 patients are excluded based on the diagnostic criteria of these groups; $\uparrow:$ parenchymal changes linked to pulmonary veno-occlusive disease may be discriminated from those associated with diffuse parenchymal lung diseases; + : features of a limited circulatory reserve may be noted in severe COPD-PH and severe IPF-PH.

Table. 4. Criteria favouring group 1 versus group 3 pulmonary hypertension (PH) [5].

for ILD), absence or modest airway or parenchymal abnormalities on CT scan, and features of exhausted circulatory reserve on cardiopulmonary exercise testing (when available) [5].

\section{TREATMENT CONSIDERATIONS OF PH IN THE COURSE OF CHRONIC LUNG DISEASES}

According to current data, there is no specific therapy for $\mathrm{PH}$ associated with lung diseases. The best recommendation is adequate treatment of the underlying lung disease. Long term oxygen therapy is used in case of hypoxemic respiratory insufficiency in patients with partial pressure of oxygen in arterial blood $\left(\mathrm{PaO}_{2}\right)$ values $<60 \mathrm{mmHg}$ to maintain arterial oxygen saturation $>90 \%$ [3]. Unfortunately, there is no proof that such treatment contribute to the prolongation of life in the patients with $\mathrm{PH}$ in the course of CLD, and it must be underlined that the use of drugs approved for $\mathrm{PAH}$ is not recommended for patients with $\mathrm{PH}$ due to lung disease because of deterioration of gas exchange. The treatment with conventional vasodilators such as calcium channel blockers (CCBs) also interferes with hypoxic pulmonary vasoconstriction by diverting pulmonary blood flow from more seriously to less seriously affected lung segments [3, 5]. Patients with suspected PAH in addition to their lung diseases (characterized by mild lung parenchymal abnormalities, symptoms insufficiently explained by lung mechanical disturbances and a haemodynamic 'PAH phenotype', such as severe $\mathrm{PH}$ with high PVR and low $\mathrm{CO}$ ) can benefit from treatment recommended for $\mathrm{PAH}$, taking into account the possible influence of the co-existing lung disease on symptoms and response to therapy.

The patients with end-stage lung disease who are suitable for lung transplantation should be referred to transplantation centres. The presence of severe PH in the course of advanced lung disease dramatically worsens the survival, especially in the patients with IPF and CPFE, so referral for lung transplantation should be done without any delay $[5,37,40]$. 


\section{CONCLUSIONS}

Echocardiography and right heart catheterization are the principal tools for the diagnosis of $\mathrm{PH}$ in chronic lung diseases. Unfortunately, current medications for treating PAH have not shown benefit in controlled trials of group 3 $\mathrm{PH}$, hence their routine use is not recommended. Patients with severe group $3 \mathrm{PH}$ should be considered for referral to expert centres or entry into clinical trials.

\section{REFERENCES}

1. Chaouat A, Bugnet A-S, Kadaoui $N$, et al. Severe pulmonary hypertension and chronic obstructive pulmonary disease.Am J Respir Crit Care Med.2005;172(2):189-194

2. Lai YC, Potoka KC, Champion HC, Mora AL, Gladwin MT. Pulmonary arterial hypertension: the clinical syndrome. Circ. Res. 2014 Jun 20;115(1):115-30.

3. Galie N, Humbert M, Vachiery JL, et al. 2015 ESC/ERS guidelines for the diagnosis and treatment of pulmonary hypertension. Eur Respir J. 2015;46(4):903-975.

4. Simonneau G, Montani D, Celermajer DS, et al. Haemodynamic definitions and updated clinical classification of pulmonary hypertension . Eur Respir J. 2019;53(1):1801913.

5. Seeger W, Adir Y, Barbera JA, et al. .Pulmonary hypertension in chronic lung diseases. J Am Coll Cardiol 2013;62:D109-D116.

6. Noureddine H, Gary-Bobo G, Alifano M, et al. Pulmonary artery smooth muscle cell senescence is a pathogenic mechanism for pulmonary hypertension in chronic lung disease. Cir Res. 2011;109(5):543-553.

7. Boerrigter BG, Bogaard HJ, Trip P, et al. .Ventilatory and cardiocirculatory exercise profilesinCOPD:theroleof pulmonary hypertension. Chest2012;142:1166-1174.

8. Wells JM, Washko GR, Han MK, et al. . Pulmonary arterial enlargement and acute exacerbations of COPD. N Engl J Med 2012; 367: 913-921.

9. Hamada K, Nagai S, Tanaka S, et al. Significance of pulmonary arterial pressure and diffusion capacity of the lung as prognosticator in patients with idiopathic pulmonary fibrosis. Chest 2007; 131: 650-656.

10. Raghu G, Behr J, Brown K, et al. Pulmonary hypertension in the patients with idiopathic pulmonary fibrosis in early course of disease: a prospective evaluation with right heart catheterization in the ARTEMISIPF study. Eur Respir J 2010;36(suppl 54):132.

11. Lettieri CJ, Nathan SD, Barnett SD, Ahmad S, Shorr AF. Prevalence and outcomes of pulmonary arterial hypertension in advanced idiopathic pulmonary fibrosis. Chest 2006;129:746-752.

12. Shorr AF, Wainright JL, Cors CS, Lettieri CJ, Nathan SD. Pulmonary hypertension in patients with pulmonary fibrosis awaiting lung transplant. Eur Respir J 2007;30:715-721.

13. Nathan SD, Shlobin OA, Ahmad S. Serial development of pulmonary hypertension in patients with idiopathic pulmonary fibrosis. Respiration 2008; 76: 288-294.

14. Behr J, Ryu JH. Pulmonary hypertension in interstitial lung disease. Eur Respir J 2008;31:1357- J.H.1367.

15. Raghu G, Nathan SD, Behr J, et al. Pulmonary hypertension in idiopathic pulmonary fibrosis with mild-to-moderate restriction. Eur Respir J 2015;46(5):1370-1377.

16. Alhamad EH, Al-Boukai AA, Al-Kassimi FA, et al. Prediction of pulmonary hypertension in patients with or without interstitial lung disease: reliability of CT findings. Radiology. 2011 Sep; 260(3):875-83.

17. Minai $0 A$, Santacruz JF, Alster JM, et al. Impact of pulmonary hemodynamics on 6-min walk test in idiopathic pulmonary fibrosis. Respir Med 2012;106:1613-1621.
18. Boutou AK, Pitsiou GG, Trigonis I, et al. Exercise capacity in idiopathic pulmonary fibrosis: the effect of pulmonary hypertension. Respirology, 2011; 16:451-458.

19. Kimura M, Taniguchi $H$, Kondoh $Y$, et al. Pulmonary hypertension as a prognostic indicator at the initial evaluation in idiopathic pulmonary fibrosis. Respiration. 2013;85:456-463

20. Cottin V, Le Pavec J, Prévot G, et al. Pulmonary hypertension in patients with combined pulmonary fibrosis and emphysema syndrome. Eur Respir J, 2010;35:105-108.

21. Hoeper MM, Behr J, Held M, et al. Pulmonary hypertension in patients with chronic fibrosing idiopathic interstitial pneumonias. PLOS One 2015;10:e0141911.

22. Cottin V, Nunes H, Brillet PY, et al. Combined pulmonary fibrosis and emphysema: a distinct underrecognised entity. Eur Respir J 2005;26:586-593.

23. Mejía M, Carrillo G, Rojas-Serrano J, et al. Idiopathic pulmonary fibrosis and emphysema: decreased survival associated with severe pulmonary arterial hypertension. Chest 2009;136:10-15.

24. Shorr AF, Helman DL, Davies DB, Nathan SD. Pulmonary hypertension in advanced sarcoidosis: epidemiology and clinical characteristics. Eur Respir J. 2005;25(5):783-8.

25. Boucly A, Cottin V, Nunes H, et al. Management and long-term outcomes of sarcoidosis-associated pulmonary hypertension. Eur Respir J 2017;50(4).

26. Boucly A, Cottin V, Nunes H, et al. Management and long-term outcomes of sarcoidosis-associated pulmonary hypertension. Eur Respir J 2017;50:1700465.

27. Baughman RP, Shlobin OA, Alhamad EH, et al. Clinical features of sarcoidosis associated pulmonary hypertension: results of a multinational registry. Res Med 2018;139:72-78.

28. Nunes H, Humbert M, Capron F, et al. Pulmonary hypertension associated with sarcoidosis: mechanisms, haemodynamics and prognosis. Thorax 2006;61:68-74.

29. Hoeper MM, Bogaard HJ, Condliffe R et al. Definitions and diagnosis of pulmonary hypertension. J Am Coll Cardiol 2013;62(suppl D):D42-50.

30. Coghlan JG, Denton CP, Grunig E, et al. Evidence-based detection of pulmonary arterial hypertension in systemic sclerosis: the DETECT study. Ann Rheum Dis 2014;73:1340-1349.

30. Avouac J, Airo P, Meune Cet al. Prevalence of pulmonary hypertension in systemic sclerosis in European Caucasians and metaanalysis of 5 studies. J Rheumatol 2010;37:2290-2298.

31. Greiner $S$, Jud A, Aurich $M$, et al. Reliability of noninvasive assessment of systolic pulmonary artery pressure by Doppler echocardiography compared to right heart catheterization: analysis in a large patient population. J Am Heart Assoc 2014;3:e001103

32. Yagi $M$, Taniguchi $H$, Kondoh $Y$, et al. CT-determined pulmonary artery to aorta ratio as a predictor of elevated pulmonary artery pressure and survival in idiopathic pulmonary fibrosis. Respirology. 2017;22(7):1393-1399.

33. Arcasoy SM, Christie JD, FerrariVA, et al. Echocardiographic assessment of pulmonary hypertension in patients with advanced lung disease. Am J Respir Crit Care Med 2003;167:735-740.

34. Fisher MR, Criner GJ, Fishman AP, et al. Estimating pulmonary artery pressures by echocardiography in patients with emphysema. Eur Respir J 2007;30:914-921.

35. Yagi M, Taniguchi H, Kondoh Y, et al. CT-determined pulmonary artery to aorta ratio as a predictor of elevated pulmonary artery pressure and survival in idiopathic pulmonary fibrosis. Respirology 2017;22:13931399. 
36. Zisman DA, Karlamangla AS, Kawut SM, et al. Validation of a method to screen for pulmonary hypertension in advanced idiopathic pulmonary fibrosis. Chest 2008; 133: 640-645.

37. Szturmowicz M, Kacprzak A, Błasińska-Przerwa K, Kuś J. Pulmonary hypertension in the course of diffuse parenchymal lung diseases - state of art and future considerations. Pneumonol Alergol Pol 2015;83(4):312-323.

38. Hoeper MM, Lee SH, Voswinckel R, et al. Complications of right heart catheterisation procedures in patients with pulmonary hypertension in experienced centers. J Am Coll Cardiol 2006;48(12):2546-2552.

39. Nathan SD, Cottin V. Chapter 12. Pulmonary hypertension in patients with idiopathic pulmonary fibrosis. Eur Respir Monogr 2012;57:148-160.

40. Nathan SD, Barbera JA, Gaine SP, et al. Pulmonary hypertension in chronic lung disease and hypoxia. Eur Respir J 2019;53:1801914.

\section{ORCID and contributionship:}

Sylwia Łukasik - 0000-0002-1071-7262 ${ }^{A, B, D}$

Dariusz Łukasik - 0000-0002-7692-7561 A,B,D

Michał Tomaszewski - 0000-0001-6993-2154 A,E,F

Weronika Topiła - 0000-0002-3997-9952 A,E,F

Agnieszka Wojtkowska - 0000-0001-9219-9763 A,D

Aleksandra Szopa - 0000-0002-7756-2904 ${ }^{A, D}$

Andrzej Wysokiński - 0000-0002-4562-9705 A,E

\section{Conflict of interest}

Authors declare no conflict of interest

\section{CORRESPONDING AUTHOR} Michał Tomaszewski

Department of Cardiology, Medical University of Lublin, Poland 8 (SPSK Nr 4) Jaczewskiego str., 20-090 Lublin, Poland

tel: +48-81-7244151

e-mail: tomaszewskimd@gmail.com

Received: 06.07.2020

Accepted: 07.09.2020

A - Work concept and design, B - Data collection and analysis, C - Responsibility for statistical analysis, D-Writing the article, $\mathbf{E}$-Critical review, $\mathbf{F}-$ Final approval of the article 